\title{
Are Corticosteroids the Mainstay of Treatment for Multisystem Inflammatory Syndrome in Children? ${ }^{1}$
}

\author{
Darko Richter ${ }^{2}$ \\ Department of Paediatrics, University Hospital Center - Zagreb, Croatia \\ Correspondence: darkorichter@gmail.com; Tel.: + 385915076396
}

Received: August 10, 2021; Accepted: August 11, 2021

Key Words: Multisystem Inflammatory Syndrome in Children • Intravenous Immunoglobulin • Corticosteroids.

This issue of CEJoP brings an important case series of 13 children with SARS-CoV2 related multisystem inflammatory syndrome (MIS-C) treated at the University Clinical Centre Tuzla during the 6 months up to April 2021 (1). The Tuzla Canton has a population of about 450.000 . This gives an incidence of 4.8 cases of MIS-C per 1 million general population per month, which is remarkably comparable to the incidence of 5.1 found in a large US study (2). The median duration of prehospital illness was 4 days (range 2-7), and the median delay to initiation of anti-inflammatory therapy was 1 day (range 0-3). Seven patients received intravenous immunoglobulin (IVIG) in combination with methylprednisolone while 6 patients were treated with methylprednisolone alone due to the short supply of IVIG. Despite this unplanned imbalance in treatment, the outcomes were not different for those with or without IVIG. The median hospital stay was 13 days (range 4-17) with recovery in all

${ }^{1}$ Invited Commentary on "Ćosićkić A, Rakovac Tupković L, Tihić N, Selimović A, Alić A, Halilbašić M, et al. Multisystem Inflammatory Syndrome in Children (MIS-C) Associated with SARS-CoV-2 Infection: A Single Center Experience. Central Eur J Paed. 2021;17(2):69-78. 10.5457/p2005-114.291.”

${ }^{2}$ Retired. but one girl who died in the intensive care unit (she did receive IVIG). All three patients with cardiovascular abnormalities did receive IVIG. Improvement was seen in all 12 surviving patients within 48-72 hours of initiating anti-inflammatory treatment. The study of 518 US patients by Son et al. showed that IVIG + corticosteroids resulted in a significantly lower relative risk of developing new or persistent cardiovascular changes than IVIG alone $(\mathrm{RR}=0.56)$ (3). In a retrospective French cohort, Ouldali et al. found that IVIG + corticosteroids, vs. IVIG alone, had a lower risk of treatment failure as assessed by the course of fever and several other important outcomes, including death (odds ratios $0.18-0.25$ ) (4). Finally, an international consortium analyzed 614 children from 32 countries and found no significant differences among 3 treatment schemes: IVIG alone, corticosteroids alone, and IVIG + corticosteroids (5). However, when the analysis was narrowed to the subgroup of patients strictly conforming to WHO criteria for MIS-C (490 patients), a slight difference favoring corticosteroids over IVIG alone was detected. The studies so far make corticosteroids pivotal to all therapeutic schemes. The observations reported in this issue further support the role of corticosteroids in the treatment of MIS-C. As usual, we need prospective 
randomized, controlled, double blind trials to reach a fully reliable scientific conclusion.

Conflict of Interest: The author declares that he has no conflict of interest.

\section{References}

1. Ćosićkić A, Rakovac Tupković L, Tihić N, Selimović A, Alić A, Halilbašić M, et al. Multisystem Inflammatory Syndrome in Children (MIS-C) Associated with SARSCoV-2 Infection: A Single Center Experience. Central Eur J Paed. 2021;17(2):69-78. doi:10.5457/p2005-114.291.

2. Payne AB, Gilani Z, Godfred-Cato S, Belay ED, Feldstein LR, Patel MM, Randolph AG, et al. Incidence of Multisystem Inflammatory Syndrome in Children Among US Persons Infected With SARS-CoV-2. JAMA
Netw Open. 2021;4(6):e2116420. doi: 10.1001/jamanetworkopen.2021.16420. PMID: 34110391; PMCID: PMC8193431.

3. Son MBF, Murray N, Friedman K, Young CC, Newhams MM, Feldstein LR et al. Multisystem inflammatory syndrome in children - initial therapy and outcomes. N Engl J Med 2021;385(1):23-34. DOI: 10.1056/NEJMoa2102605.

4. Ouldali N, Toubiana J, Antona D, Javouhey E; Madhi F, Lorrot $\mathrm{M}$ et al. Association of intravenous immunoglobulins plus methylprednisolone vs immunoglobulins alone with course of fever in multisystem inflammatory syndrome in children. JAMA. 2021;325(9):855-64. doi:10.1001/jama.2021.0694.

5. McArdle AJ, Vito O, Patel H, Seaby EG, Shah P, Wilson $\mathrm{C}$ et al. Treatment of multisystem inflammatory syndrome in children. N Engl J Med. 385(1):11-22. doi:10.1056/ NEJMoa2102968. 